\title{
Enhance Students' Learning in Business Statistics Class Using Video Tutorials
}

\begin{abstract}
Guolin Lai ${ }^{1}$, Zhiwei Zhu ${ }^{2}$, and Douglas Williams ${ }^{3}$
Abstract: As a supplement to traditional classroom instruction, online video tutorials were created and made available as just-in-time support to enhance undergraduate business students' academic performance in a required introductory business statistics course. The study showed the availability of video tutorials enriched students' learning experiences and enhanced their academic performance. The results suggest that the learning benefits of the video tutorials were instrumental to those students with a final course grade $B$ or $C$ because these students were struggling to understand the course materials in the class. While those students with a final grade of $A, D$, or $F$ might believe that they either totally understood everything or they were absolutely lost in the class. In either case, these students might believe that studying the video tutorials added no more value to their understanding of the materials presented in the class.
\end{abstract}

Keywords: Statistics learning, multimedia learning, video tutorials, technology-enhanced pedagogy, technology integration, instructional technology

\section{Introduction}

Statistical literacy, statistical reasoning, and statistical thinking are increasingly applied in various industries as today's business becomes more digitalized (Ben-Zvi \& Garfield, 2004; Franklin \& Garfield, 2006; Lane, Mansour, \& Harpell, 1993; Philip \& Schultz, 1994). To respond to this trend, the accredited colleges of business school in the United States have required business students to take at least one statistics course in their degree program. However, the core-required business statistic course has been viewed by many students as being anxiety-producing and the most difficult to understand (Berenson, Ramnarayanan, \& Oppenheim, 2015; Swanson, Meinert, \& Swanson, 1994). Students either had a very negative learning experience with the course (Hogg, 1991) or regarded it as an obstacle preventing them from receiving their business degrees (Perney \& Ravid, 1990). As a result, many students tend to take this course as late as possible in their degree program (Onwuegbuzie \& Wilson, 2003; Roberts \& Bilderback, 1980; Zeidner, 1991). In the College of Business Administration where the first two authors are employed, two business statistics courses are required for all business majors. The authors' experience of teaching business statistics has been consistent with what is reported in the literature. Surveys of graduating seniors conducted by our college each semester indicate that our students constantly rank both statistics courses as the least valued and yet most difficult classes in their degree program. We, as business statistics instructors, constantly struggle to find ways to help students learn business statistics more

\footnotetext{
${ }^{1}$ Department of Management, University of Louisiana at Lafayette, P. O. Box 43570, Lafayette, LA 70504-3570, glai@louisiana.edu

${ }^{2}$ Department of Management, University of Louisiana at Lafayette, P. O. Box 43570, Lafayette, LA 70504-3570, zzhu@louisiana.edu

${ }^{3}$ Center for Innovative Learning and Assessment Technologies, University of Louisiana at Lafayette, P. O. Box 42051, Lafayette, LA 70504, dwilliams@louisiana.edu
} 
effectively. We are turning our attention to the efficacy and affordances of technologies integrated into our statistics teaching.

Technology has long been recognized as a way of enriching college students' learning experiences and enhancing their academic performance. For example, the Board of Directors of the American Statistical Association endorsed a set of six guidelines for teaching the introductory college statistics course(s). The significant use of technology in understanding concepts and analyzing data is one of the guidelines (Franklin \& Garfield, 2006). To explore the role of technology in improving students' learning, Chance, Ben-Zvi, Garfiled, and Medina (2007) synthesized developments in the use of technological tools in teaching introductory statistics. They argued that technology use has brought about positive changes in content, pedagogy, and course format. Similarly, Meletiou-Mavrotheris, Lee and Fouladi (2007) stated that students' engagement with technology may have a positive impact on their motivation for learning statistics, on their enjoyment and appreciation of statistics, and on their increased exposure and familiarity with the practical aspects of statistics. Haughton and Kelly (2015) created two learning environments for teaching an introductory business statistics course, a classroom-based environment and a flippedhybrid environment. They found that students in the hybrid class did better on the final exam, but there were no significant differences in the final grades. Martin (2011) taught two business statistics classes, one in a computer lab and one in a traditional classroom. She found that students in a traditional classroom performed slightly better on the exam due to the distractions that are more prevalent in the lab, including emailing, web browsing, and social networking. Larwin and Larwin (2011a) believe that the traditional talk and chalk lecture are not enough for students to really understand the concepts. They used random distribution theory and bootstrapping simulations to teach business statistics and found students performed better on exams. Through a meta-analysis, Larwin and Larwin (2011b) found that computer-assisted instruction, if properly applied as an enhancement or supplement to small sections of statistics, can be very beneficial to student achievement.

Statistical reasoning and thinking are a higher level cognition that students need time to develop. Unlike an experienced professional or an expert in statistics, students do not have schemata of statistical problem solving in their minds. Reviewing is an important strategy for committing learning to long-term memory. Constant review of demonstrated problem solving from a subject expert can help novices develop such schemata. Video tutorials are a type of rich media as defined by Clark and Mayer (2003), which has web capabilities and thus can be transmitted from one source to various receivers. The use of screen capture and audio technology can help provide more "human" learning experiences to engage students in their learning process. With Web-based solved statistical problems as a supplement to traditional classroom instruction, online video tutorials have the potential to provide students with unlimited and sustained support to develop their schemata of statistical problem solving. Moreover, video tutorials allow professors to model proper statistical reasoning and thinking to enhance students' statistical literacy. Modeling is strongly related to cognitive apprenticeship pedagogy (Collins, Brown, \& Holum, 1991; Collins, Brown, \& Newman, 1989), and is usually applied together with coaching and fading. For example, statistics instructors, guided by cognitive apprenticeship models, while modeling the statistical problem solving procedure, can make their statistical reasoning and statistical thinking explicit in video tutorials to students by explaining what they are doing and thinking, how they do it, and why they do it in that particular fashion. Contingent on students' 
development and growth in their statistical capability, the instructor can adjust the level of coaching available in the video tutorials.

Video tutorials have been applied in statistics education to enrich students' learning experiences and to enhance their academic performance. Statistics textbook publishers tend to include some animated solutions to problems in their online resources which are available to both instructors and students. Mixed results of the effectiveness of video tutorials are available in the literature. Aberson (2002) used an interactive Web-based tutorial to supplement instruction on statistical power. Students rated the tutorial as clear, useful, and easy to use, and they reported increased comfort with the topic after using the tutorial. Moreover, students who used the tutorial outperformed those who did not. DeVaney (2009) created video tutorials to help students use SPSS (statistics analysis software) to conduct statistical analyses rather than using formulas to perform calculations by hand. Qualitative data indicated students' positive perceptions of the tutorials. However, comparisons of course sections with and without access to the tutorials showed no statistically significant difference in students' course performance. Similarly, Lloyd and Robertson (2012) investigated the effect of screencast tutorials on students' statistics learning outcomes. Contrary to DeVaney's (2009) systemic use of video tutorials throughout the course, Lloyd and Robertson (2012) only examined one video tutorial demonstrating the following steps of statistical analysis: data entry, independent samples test in SPSS, and output interpretation. The results show that the tutorial significantly enhanced students' performance in statistics learning, especially for higher level of statistical knowledge. McDaniel and Green (2012) found that the use of online instructional modules, which combine an applet, audio-visual tutorials, and guided discovery questions, contributed to an increase in students' understanding of sampling variability concepts. Also, viewing videos of statistics-in-action can positively affect students' attitudes towards statistics (Allredge, Johnson, \& Sanchez, 2006).

The use of technology in statistics education seems to be a challenge for statistics educators (Ben-Zvi \& Garfield, 2008; Zieffler et al., 2008) because it still needs more empirical research to answer the questions educators will face (Garfield \& Ben-Zvi, 2007). Zieffler et al. (2008) further point out that the lack of graduate programs and courses to prepare researchers in statistics education creates several problems. These problems include disconnection, fragmentation, and difficulty in accessing research on the teaching and learning of statistics. Researchers in statistics education are trying to find best practices to enrich student learning experiences, and more importantly, to enhance their statistical learning performance. As Chance et al. (2007) argued, technology adoption in statistics learning can contribute to changes in content, pedagogy, and course format. However, there is still a lack of research examining and exploring the effects of technology-enhanced pedagogy on business students' statistical learning performance. More research is needed to investigate the affordances of systemic integration of online video tutorials as a supplement to traditional classroom instruction. Hence, the purpose of the current study is to investigate whether online video tutorials, if consistently provided as a supplement to traditional classroom instruction throughout the semester, enhanced students' statistical performance. Specifically, this study investigates the following two research questions:

1. Is there a relationship between students' total number of video views and their final course grade in an introductory business statistics class? 
2. Which, if any, of the factors such as GPA, self-reported math capability, total number of video views, MATH 100 \& 105 grade (statistics prerequisites), weekly employment work hours, and weekly study hours are significantly related to students' final course grade?

\section{Methods}

\section{Course Description and Participants}

The research setting for the study is the business college of a state university in the southern United States. One author taught two sections of a required undergraduate course, Fundamentals of Business Statistics, in Spring 2013. The topics in the course include descriptive statistics, probability and probability distributions, sampling methods and the central limit theorem, confidence intervals, one-sample tests of hypotheses, and linear regression and correlation. The course was delivered in a traditional classroom setting, using lectures as main content delivery mechanism. Meanwhile, the author made extensive use of Moodle, a course management system, to support and engage students' statistics learning. On Moodle, the author (a) posted instructional/learning resources such as statistics tables, chapter PowerPoint slides, book examples presented in Microsoft Excel, and video tutorials; (b) provided opportunities to engage students in how-to discussion forums; and (c) assessed students' learning through online quizzes.

Participants for the study were 75 students who completed the two sections. Only 73 students were present when demographic information was collected. Table 1 summarizes the demographics for all 73 students who completed the survey. Table 2 summarizes other data collected either from the university system (adjusted GPA, MATH 100 and MATH105 grade) or from the survey (self-report math capability, weekly employment work hours, and weekly study hours).

\section{Video Tutorials}

There are many statistics-related video tutorials available on the internet, and can be easily found at www.youtube.com, for example, or at the online portal provided by textbook publisher. However, the author decided to design and develop his own video tutorials hoping to provide students with content presentation/explanation consistent with that of classroom instruction. Mayer's (2005) cognitive theory of multimedia learning guided the design and development of the video tutorials. While designing and developing the video tutorials, the author followed the following five steps that Mayer (2001) prescribes:

(A) selecting relevant words for processing in verbal working memory, (b) selecting relevant images for processing in visual working memory, (c) organizing selected words into verbal mental model, (d) organizing selected images into a visual mental model, and (e) integrating verbal and visual representations as well as prior knowledge" (Mayer, 2001, p. 54).

Throughout the semester, the first author made available 40 video tutorials on Moodle that ranged from 3 to 13 minutes in length. Typically, a video tutorial covered a solved statistical 
problem from the textbook (see Figure 1) which explained one or two key statistics concepts or techniques. In class, the author also demonstrated how to solve the same problem(s). Tools and software utilized included (1) Microsoft Excel for problem solving and content presentation, (2) Microsoft Paint, software used to create images incorporated in the tutorials like the bell-shaped curve graph in Figure 1, (3) Panopto Recorder, technology for screen capture, and (4) a microphone used to record narration. In the tutorials, the author explained what statistical concepts were relevant, what statistical techniques were needed, and how and why the problem was solved. Thus these video tutorials only served as a supplement to, not a replacement for, traditional instruction in the classroom. After the classroom instruction, the author made available the video tutorials on Moodle as clickable links to serve as just-in-time support for students to review. As long as students have internet access, they can view the tutorials anytime, anywhere, and as many times as they desire. The author hoped that the availability of the video tutorials would not only enrich students' statistics learning experiences, but ultimately contribute to the improvement of their statistical learning performance.

Table 1: Summary of students' demographic data

\begin{tabular}{|c|c|c|c|}
\hline Demographic & Value & \# Students & Percent \\
\hline \multirow[t]{3}{*}{ Gender } & Female & 32 & $43.8 \%$ \\
\hline & Male & 41 & 56.2 \\
\hline & Total & 73 & 100.00 \\
\hline \multirow[t]{5}{*}{ Ethnicity } & Caucasian & 49 & 67.1 \\
\hline & African-American & 16 & 21.9 \\
\hline & Hispanic & 2 & 2.7 \\
\hline & $\begin{array}{l}\text { Asian/Asian-American/Pacific } \\
\text { Islander }\end{array}$ & 6 & 8.2 \\
\hline & Total & 73 & 100.00 \\
\hline \multirow[t]{4}{*}{ Age Group } & $18-23$ & 63 & 86.3 \\
\hline & $23-28$ & 8 & 11.0 \\
\hline & $33-38$ & 2 & 2.7 \\
\hline & Total & 73 & 100.00 \\
\hline
\end{tabular}

\section{Data Sources}

There were four data sources in this study. A brief description of the data sources were provided below.

Student demographics. Selected information regarding demographics and mathematics capability was collected. Demographic information included gender, ethnicity, age, GPA, number of credit hours, number of weekly employment hours, and number of weekly study hours for the class. Other questions were related to their mathematics capability including a selfreported scale of math skills, grade earned in the prerequisite math class, and whether they had repeated the math class.

Total number of video views. The Moodle course management system has the capability to track student use of each video tutorial including the date and time of access, and the overall 
number of accesses. The instructor collected and recorded students' total number of video views using report mechanisms available in Moodle.

Academic performance. Throughout the semester, students took four exams (none online) in classroom. Students' numerical grades of each exam were collected. Their final letter grades for the course were also recorded.

Student evaluation of instruction (SEI). Students' online voluntary evaluation of instruction was collected by the university at the end of the semester. The instructor received the SEI results after the university aggregated and analyzed the data.

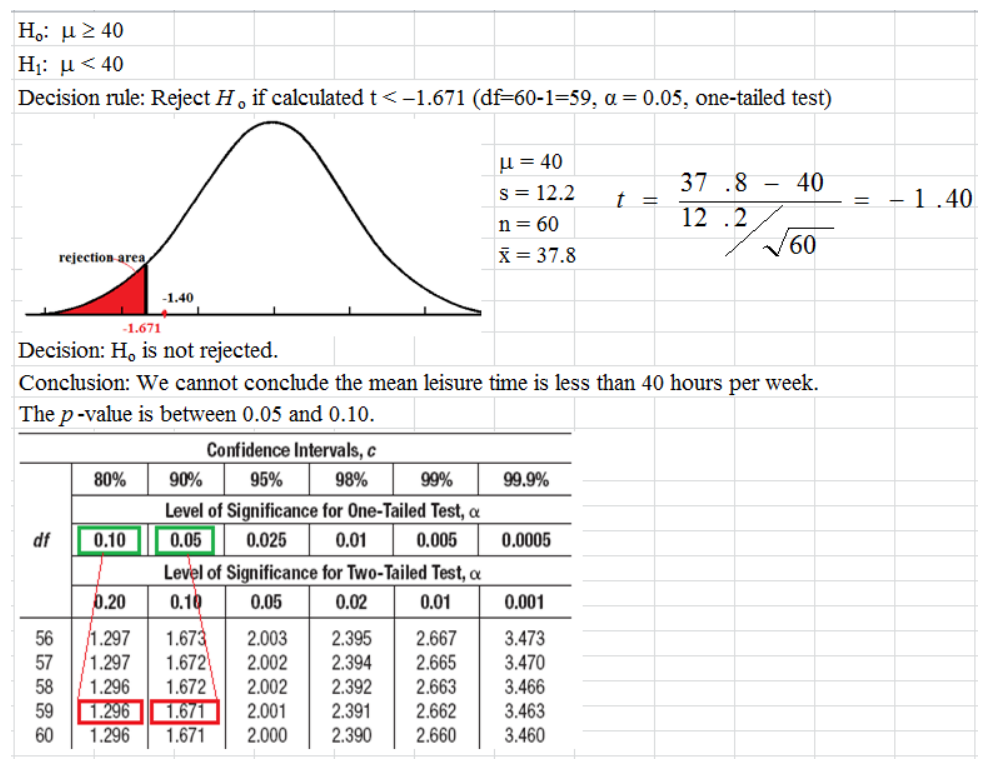

Figure 1. A video tutorial screen on one-sample hypothesis testing.

\section{Data Analysis}

A scale ranging from 0 to 4 was used to code the final grades achieved in the prerequisite math classes and in the statistics class $(F=0 ; D=1 ; C=2 ; B=3$; and $A=4)$. Weekly hours spent for employment were numerically coded by the hours range identified, for example, 0 for no employment, 1 for " 1 up to 5 hours", 10 for " 40 or more hours), and so on. IBM SPSS Statistics version 21 was used to conduct all statistical analyses including correlation analysis, independent two-sample t test, ANOVA, and linear regression analysis. Due to tradition and convenience, we used a significant level of 0.05 for all statistical analyses.

\section{Table 2: Summary of other related data}

\begin{tabular}{|c|l|l|l|}
\hline Demographic & \multicolumn{1}{|c|}{ Value } & \multicolumn{1}{c|}{$\begin{array}{c}\text { P } \\
\text { Students }\end{array}$} & \multicolumn{1}{c|}{ Percent } \\
\hline \multirow{3}{*}{ Adjusted GPA } & $<2$ & 3 & $4 \%$ \\
\cline { 2 - 5 } & {$[2-2.5)$} & 23 & 30.7 \\
\cline { 2 - 5 } & {$[2.5-3)$} & 22 & 29.3 \\
\cline { 2 - 5 } & {$[3-3.5)$} & 18 & 24 \\
\hline
\end{tabular}

Journal of Teaching and Learning with Technology, Vol. 6, No. 1, January 2017 


\begin{tabular}{|c|c|c|c|}
\hline & $\geq 3.5$ & 9 & 12 \\
\hline & Total & 75 & 100.00 \\
\hline \multirow{4}{*}{$\begin{array}{l}\text { Self-reported } \\
\text { Math } \\
\text { Capability }\end{array}$} & {$[1-5)$} & 11 & 15.1 \\
\hline & {$[5-7)$} & 18 & 24.7 \\
\hline & $\geq 7$ & 44 & 60.2 \\
\hline & Total & 73 & 100.00 \\
\hline \multirow{5}{*}{$\begin{array}{l}\text { MATH } 100 \& \text { \& } \\
105 \text { Grade }\end{array}$} & $\mathrm{A}$ & 20 & 26.7 \\
\hline & B & 11 & 14.7 \\
\hline & $\mathrm{C}$ & 27 & 36 \\
\hline & Waived & 17 & 22.7 \\
\hline & Total & 75 & 100.00 \\
\hline \multirow{7}{*}{$\begin{array}{l}\text { Weekly } \\
\text { Employment } \\
\text { Work Hours }\end{array}$} & 0 & 8 & 11.0 \\
\hline & $1-10$ & 8 & 11.0 \\
\hline & $10-20$ & 21 & 28.8 \\
\hline & $20-30$ & 26 & 35.6 \\
\hline & $30-40$ & 7 & 9.6 \\
\hline & $\geq 40$ & 3 & 4.1 \\
\hline & Total & 73 & 100.0 \\
\hline \multirow{5}{*}{$\begin{array}{l}\text { Weekly Study } \\
\text { Hours }\end{array}$} & {$[1-1.5]$} & 15 & 20.5 \\
\hline & {$[2-3]$} & 35 & 47.9 \\
\hline & {$[3.5-4.5]$} & 15 & 20.5 \\
\hline & $>4.5$ & 8 & 11.0 \\
\hline & Total & 73 & 100.00 \\
\hline
\end{tabular}

\section{Research Findings}

For a total of 40 individual video tutorials posted on Moodle, descriptive statistics indicated that the range of the students' total number of video views is 0 to $139(\mathrm{M}=24.04, \mathrm{SD}=28.64)$. This information is illustrated in Table 3 . The descriptive statistics of the total number of video views for students in each final grade category was presented in Table 4 . ANOVA showed that the mean total number of video views for students with different grades were not all equal, with $\mathrm{F}(4,74)=$ $2.592, \mathrm{p}=.044$, and effective size $\eta=.359$ and $\omega=.280$. Further statistical analyses revealed insignificant differences between these grade groups: between $\mathrm{A}$ and $\mathrm{B}(\mathrm{t}=-1.585, \mathrm{p}=.124)$, between $\mathrm{A}$ and $\mathrm{C}(\mathrm{t}=-1.451, \mathrm{p}=.158)$, between $\mathrm{A}$ and $\mathrm{D}(\mathrm{t}=-.156, \mathrm{p}=.878)$, between $\mathrm{A}$ and $\mathrm{F}$ $(\mathrm{t}=.676, \mathrm{p}=.506)$, between $\mathrm{B}$ and $\mathrm{C}(\mathrm{t}=.180, \mathrm{p}=.858)$, between $\mathrm{B}$ and $\mathrm{D}(\mathrm{t}=1.519, \mathrm{p}=.140)$, between $C$ and $D(t=1.371, p=.182)$, and between $D$ and $F(t=-1.308, p=.204)$. Significant differences were only identified between $\mathrm{B}$ and $\mathrm{F}(\mathrm{t}=2.801, \mathrm{p}=.008)$, and $\mathrm{C}$ and $\mathrm{F}(\mathrm{t}=2.451, \mathrm{p}$ $=.02$ ).

Correlation analyses were conducted for students' total number of video views versus each of the following variables of interest. The correlations between total number of video views and each of the variables are: final course grade, $r=0.175, p=0.133$; prerequisite Math $100 \& 105$ combined, $\mathrm{r}=.03, \mathrm{p}=.800$; weekly employment hours, $\mathrm{r}=-.076, \mathrm{p}=.524$; self-reported math capability, $\mathrm{r}=.345, \mathrm{p}=.003$; GPA, $\mathrm{r}=.463, \mathrm{p}=.000$; and weekly study hours on the course, $\mathrm{r}$ $=.324, \mathrm{p}=.005$. These results indicate that there is very little linear relationship between total number of video views and final course grade, prerequisite Math $100 \& 105$ combined, and weekly Journal of Teaching and Learning with Technology, Vol. 6, No. 1, January 2017 
employment work hours. Meanwhile, statistically significant correlations exist between total number of video views and self-reported math capability, GPA, and weekly study hours.

Table 3: Total video tutorial view frequency

\begin{tabular}{|l|c|}
\hline Total Number of Video Views & Number of Students \\
\hline 0 & 9 \\
\hline 1 up to 10 & 21 \\
\hline 10 up to 20 & 16 \\
\hline 20 up to 30 & 7 \\
\hline 30 up to 40 & 6 \\
\hline 40 up to 60 & 6 \\
\hline 60 up to 80 & 5 \\
\hline 80 up to 100 & 4 \\
\hline$\geq 100$ & $\underline{1}$ \\
\hline & 75 \\
\hline
\end{tabular}

Table 4: Mean of video views by grades

\begin{tabular}{|l|c|l|l|}
\hline Grades & Mean & Standard Deviation & Number of Students \\
\hline A & 14.90 & 26.42 & 10 \\
\hline B & 32.27 & 29.69 & 22 \\
\hline C & 34.16 & 37.19 & 19 \\
\hline D & 16.44 & 14.20 & 9 \\
\hline F & 9.80 & 10.63 & 15 \\
\hline
\end{tabular}

\section{Discussions}

\section{Implications of Research Findings}

Educators in higher education are increasingly provided with various digital teaching materials/resources from textbook publishers. Students can also easily retrieve learning materials/resources from the Internet, for example, Wikipedia, Google and Youtube, which have been increasingly touted as learning tools (Quinn, 2004). Moreover, with the exponential growth of computer technology, and development and easy access to various educational tools, educators find themselves better equipped to design and develop digital learning resources, for example, video tutorials used in the study. In their statistical learning process, other than the routine in-class instruction, students in this study seemed to enjoy the availability of video tutorials on Moodle; subsequently, their academic performance benefited from their access to such resources. The results of the study are in agreement with the literature that resources as performance support mechanism are integral to learning, and recent years have witnessed the resurgence of resourcebased learning in various learning environments (Freeman, Patel, Routen, Ryan, \& Scott, 2013; Hill \& Hannafin, 2001). 
ANOVA showed that the mean total number of video views differed by students' final course grades, and further analyses identified significant differences between students earning grades $\mathrm{B}$ and $\mathrm{F}$, and between those earning grades $\mathrm{C}$ and $\mathrm{F}$. These results suggest that the learning benefits of the video tutorials are instrumental to those students (a) aspiring to earn a higher grade, (b) with average statistical capability, and (c) who struggled to understand the course materials during the limited class time. From Table 3, it is clear to see that students earning a final grade of $\mathrm{B}$ or $\mathrm{C}$ viewed the video tutorials the most on average. This suggests that these students might not fully understand the classroom instruction, and need sustained support to enable them to review the learning materials. The video tutorials posted on Moodle exactly served that purpose. The constant availability of the video tutorials on Moodle provided these students with unlimited justin-time opportunities to revisit the learning resources/materials to enhance their understanding of statistical concepts and their capability of solving problems. These video tutorials eventually increased their learning and recall of the course materials which otherwise might have been lost during the once-and-for-all classroom instruction. The efficacy of these video tutorials in enhancing students' statistics learning was further corroborated by the comments that students provided in the Student Evaluation of Instruction (SEI). The SEIs were collected by the university, and students voluntarily completed the online evaluation form. For example, one student commented that "He went out of his way and provided additional tools and tutorials online to aid in the problems we worked in class." And another student wrote "He provided a lot of outside help with additional video presentations as to how to work a problem which really helped me out." On the contrary, the students earning a final grade of A were likely those who understood everything in classroom and thus did not feel the need to review the tutorials. Whereas the students earning a final grade of D or F were probably those who were lost in classroom and showed no interest in learning more from the video tutorials.

As evidenced by this study, technology has impacted on teaching and learning business statistics. However, such potential improvement may be difficult to realize without judicious consideration of pedagogy. Learning is a process that involves multifaceted changes in attitudes, beliefs, capabilities, knowledge structures, mental models, and/or skills (Spector, 2001). As Meletiou-Mavrotheris et al. (2007) point out, technology alone will not adequately contribute to the improvement of students' understanding and performance. Technology-enhanced pedagogy is likely to have potential in helping students not only enrich their learning experiences, but also enhance their academic performance (Garfield, 1995; Garfield \& Ben-Zvi, 2007). Because of that, Moore (1997) has long urged that a reform of statistics instruction and curriculum should be based on strong synergies among content, pedagogy, and technology. He cautioned instructors to choose pedagogically appropriate technology for students' learning and enhancement. The study showed that the availability of video tutorials, if pedagogically provided as supplementary learning resources to traditional classroom instruction, enriched students' learning experiences and enhanced some students' learning performance.

In this study, traditional classroom teaching supplemented by online video tutorials improved some students' learning performance in business statistics classes. The results of the study add to a growing body of the literature that suggests technology-enhanced pedagogy, if properly integrated in the classroom teaching, effectively impact on students' learning performance. The students' learning gain in the study might encourage educators in other disciplines to consider including the pedagogical use of video tutorials into their teaching repertoire. 
It is interesting to see that the first author's technology adoption and integration efforts in teaching business statistics have been paid off. According to Massy and Zemsky (1996), there are three levels of technology adoption in higher education: (a) personal productivity aids, (b) enrichment add-ins, and (c) paradigm shift (as cited in Rogers, 2000). Personal productivity aids refer to faculty members' use of application software such as Microsoft Excel and PowerPoint to perform their tasks more efficiently and effectively. Nearly all faculty members in higher education institutions are at this level. Enrichment add-ins refer to faculty members' integration of new materials such as web page, multimedia and simulation to enhance traditional teaching and learning without changing the basic mode of instruction. This level of technology adoption is very common in higher education. Paradigm shift represents the highest level of technology adoption where faculty members redesign teaching and learning activities to take full advantage of capabilities of new technologies. This level of technology adoption is still in the emerging phase. The current study's technology-enhanced pedagogy is between Massy and Zemsky's second and third level of technology adoption. The author spent extra time and effort in preparing various learning resources, and made them available on Moodle to supplement traditional classroom instruction. The author hoped that the availability of various resources/materials would help provide a supportive learning environment to encourage student's exploration in business statistics, and thus eventually nurture an atmosphere in which questions can be freely asked, feedback promptly provided, and learning support available in a just-in-time mode.

Technology integration in classroom has great potential to enhance teaching and learning of business statistics. However, turning that potential into a reality can be a complex, multifaceted, and daunting task. Instructors need to overcome various obstacles in order to create rich learning environments with use of technology and necessary support mechanisms. Such obstacles include lack of time, lack of training/expertise, lack of access to technologies, lack of resources, lack of support, and different pedagogical belief (Fabry \& Higgs, 1997; Huffman, Goldberg, \& Michlin, 2003; Keengwe, Onchwari, \& Wachira, 2008; Keleiman, 2004; Leggett \& Persichitte, 1998; Su, 2009; Thistead \& Velleman, 1992). Most of these obstacles tend to be external to instructors and are more resource-related. According to Ertmer (2005), external obstacles are easy to overcome, but not internal obstacles, which are embedded in an instructor's philosophy of teaching and learning, and pedagogical belief. Or in other words, it is instructors' beliefs that hold back their technology adoption and integration efforts. Furthermore, the removal of the internal and the external barrier might not be sufficient to enable technology integration in classroom. According to Tsai and Chai (2012), the removal of the external barrier may facilitate teachers' technology usage; the elimination of the internal barrier may help them be committed to implement technology integration. Teachers still need to overcome third-order barriers, the lack of design thinking skills and disposition. Due to the dynamic nature of classroom context and students, teachers "should rely on some design-thinking to re-organise or create learning materials and activities, adapting to the instructional needs for different contexts or varying groups of learners" (Tsai \& Chai, 2012, p. 1058). If the third-order barriers are reduced, teachers can undertake technology integration actively and fluently.

Therefore, when faculty members are introduced to new technologies, higher education administrators need to make sure that faculty members need not only training on technological know-how, pedagogical benefits, and pedagogically sound practices related to technologies, but also training on and nurturing of design thinking skills and disposition. Meanwhile, sustained 
administrative support, technological support, and pedagogical support should be available to faculty members who have adopted new technologies.

\section{Limitations of the Study and Future Research}

This study was conducted at a single public university to investigate undergraduate business students' performance in business statistics classes when the supplementary video tutorials were available. Due to the size of the sample which included only the author's two sections of a required introductory business statistics course, both internal and external validity of the study may be limited. Future studies should be conducted utilizing a wider spectrum of participants taught by different faculty members and faculty members from other institutions.

The factors investigated in this study include self-reported math capability, prerequisite math grade, weekly employment hours, GPA, and weekly study hours. It is possible that other factors, not included in this study, might be contributing to students' total number of video views, for example, the types of devices used by students and how easily they can access to internet. Future research might consider examining these factors including motivation, learning styles/habits, self-efficacy, and access to internet technologies. Furthermore, qualitative studies may be conducted to explore what contributes to student decisions and frequency of video views, and what extra features or improvements would entice them to view video tutorials.

\section{References}

Aberson, C. L. (2002). An interactive tutorial for teaching statistical power. Journal of Statistics Education, 10(3), available at www.amstat.org/publications/jse/v10n13/aberson.html.

Allredge, J. R., Johnson, H. D., \& Sanchez, J. J. (2006). Does viewing video of statistics in action affect student attitudes. In A. Rossman \& B. Chance (Eds.), Working cooperatively in statistics education: Proceedings of the Seventh International Conference on Teaching Statistics: Boorburt, The Netherlands: International Statistical Institute.

Ben-Zvi, D., \& Garfield, J. (Eds.). (2004). The challenge of developing statistical literacy, reasoning and thinking. Dordrecht, The Netherlands: Kluwer Academic Publishers.

Ben-Zvi, D., \& Garfield, J. B. (2008). Introducting the emerging displine of statistics education. School Science and Mathematics, 108(8), 355-361.

Berenson, M. L., Ramnarayanan, R., \& Oppenheim, A. (2015). Assessing the disconnect between grade expectation and achievement in a business statistics course. Journal of Education for Business, 90(2), 72-79.

Chance, B., Ben-Zvi, D., Garfield, J. B., \& Medina, E. (2007). The role of technology in improving student learning statistics. Technology Innovations in Statistics Education, 1(1), available at escholarship.org/uc/item/8sd2t4rr. 
Clark, R. C., \& Mayer, R. E. (2003). E-learning and the science of instruction. San Francisco, CA: John Wiley and Sons, Inc.

Collins, A., Brown, J. S., \& Holum, A. (1991). Cognitive apprenticeship: making thinking visible. American Educator, 6(11), 38-46.

Collins, A., Brown, J. S., \& Newman, S. E. (1989). Cognitive apprenticeship: Teaching the crafts of reading, writing, and mathematics. In L. B. Resnick (Ed.), Knowing, learning, and instruction: Essays in honor of Robert Glaser (pp. 453-494). Hillsdale, NJ: Lawrence Erlbaum Associates.

DeVaney, T. A. (2009). Impact of video tutorials in an online educational statistics course. Journal of Online Learning and Teaching, 5(4), available at jolt.merlot.org/vol5no4/devaney_1209.htm.

Ertmer, P. A. (2005). Teacher pedagogical beliefs: The final frontier in our quest for technology integration? Educational Technology Research and Development, 53(4), 25-39.

Fabry, D. L., \& Higgs, J. R. (1997). Barriers to the effective use of technology in education: Current status. Journal of Educational Computing Research, 17(4), 385-395.

Franklin, C. A., \& Garfield, J. (2006). The GAISE project: Developing statistics eductaion guidelines for grades pre-K-12 and college courses. In G. F. Burrill \& P. C. Elliott (Eds.), Thinking and reasoning with data and chance: 2006 NCTM yearbook (pp. 345-376). Reston, VA: National Council of Teacher of Mathematics.

Freeman, H., Patel, D., Routen, T., Ryan, S., \& Scott, B. (2013). The virtual university: The internet and resource-based learning. Routledge.

Garfield, J. (1995). How students learn statistics. International statistical review, 63(1), 25-34.

Garfield, J., \& Ben-Zvi, D. (2007). How students learn statistics revisited: A current review of research on teaching and learning statistics. International statistical review, 75(3), 372-396.

Haughton, J., \& Kelly, A. (2015). Student performance in an introductory business statistics course: Does delivery mode matter? 90, 1(31-42).

Hill, J. R., \& Hannafin, M. (2001). Teaching and learning in digital environments: The resurgence of resource-based learning. Educational Technology Research and Development, 49(3), 37-52.

Hogg, R. V. (1991). Statistical education: Improvement are badly deeded. The American Statistician, 45, 342-343.

Huffman, D., Goldberg, F., \& Michlin, M. (2003). Using computers to create constructivist learning environments: Impact on pedagogy and achievement. Journal of Computers in Mathematics and Science Teaching, 22(2), 151-168. 
Keengwe, J., Onchwari, G., \& Wachira, P. (2008). Computer technology integration and student learning: Barriers and promise. Journal of Sicence Education and Technology, 17(6), 560-565.

Keleiman, G. M. (2004). Myths and realities about technology in k-12 schools: Five years later. Contemporary Issues in Technology and Teacher Education, 4(2), 248-253.

Lane, M. S., Mansour, A. H., \& Harpell, J. L. (1993). Operations research techniques: A longitudinal update 1973-1988. Interfaces, 23(2), 63-68.

Larwin, K. H., \& Larwin, D. A. (2011a). Evaluating the use of random distribution theory to introduce statistical inference concepts to business students. Journal of Education for Business, $86(1), 1-9$.

Larwin, K. H., \& Larwin, D. A. (2011b). A meta-analysis examing the impact of computer-assisted instruction on postsecondary statistics education: 40 years of research. Journal of Research on Technology in Education, 43(3), 253-278.

Leggett, W. P., \& Persichitte, K. A. (1998). Blood, sweat, and TEARS: 50 years of technology implementation obstacles. TechTrends, 43(3), 33-36.

Lloyd, S. A., \& Robertson, C. L. (2012). Screencast tutorials enhance student learning of statistics. Teaching of Psychology, 39(1), 67-71.

Martin, L. R. (2011). Teaching business statistics in a computer lab: Benefit or distraction? Journal of Education for Business, 86(4), 326-331.

Massy, W. F., \& Zemsky, R. (1996). Information technology and academic productivity. Educom Review, 31(1), 12-14.

Mayer, R. E. (2001). Multimedia learning. Cambridge, UK: Cambridge University Press.

Mayer, R. E. (2005). Cognitive theory of multimedia learning. In R. E. Mayer (Ed.), The Cambridge Handbook of Multimedia Learning (pp. 31-49). Cambridge, England: Cambridge University Press.

McDaniel, S. N., \& Green, L. B. (2012). Using applets and video instruction to foster students' understanding of sampling variability. Technology Innovations in Statistics Education, 6(1), available online at escholarship.org/uc/item/inh4n607.

Meletiou-Mavrotheris, M., Lee, C., \& Fouladi, R. T. (2007). Introductory statistics, college student attitudes and knowledge - a qualitative analysis of the impact of technology-based instruction. International Journal of Mathematical Education in Science and Technology, 38(1), 65-83.

Moore, D. S. (1997). New pedagogy and new content: The case of statistics. International statistical review, 65(2), 123-137. 
Onwuegbuzie, A. J., \& Wilson, V. A. (2003). Statistics anxiety: Nature, etiology antecedents, effects, and treatments - a comprehensive review of the literature. Teaching in Higher Education, $8(2), 195-209$.

Perney, J., \& Ravid, R. (1990). The relationship between attitudes towards statistics, math selfconcept, test anxiety and graduate students' achievement in an introductory statistics course. Paper presented at the American Educational Research Association.

Philip, G. C., \& Schultz, H. K. (1994). Operations research in medium-sized companies and the microcomputer revolution: Educational implications. Journal of Education for Business, 69(4), 217-221.

Quinn, C. N. (2004). Learning at large: Situating learning in the bigger picture of action in the world. Educational Technology, 4, 45-49.

Roberts, D. M., \& Bilderback, E. W. (1980). Reliability and validity of a statistics attitude survey. Educational and Psychological Measurement, 40(1), 235-238.

Rogers, D. L. (2000). A paradigm shift: Technology integration for higher education in the new millennium. Educational Technology Review, 1(13), 19-33.

Spector, J. M. (2001). An overview of progress and problems in educational technology. Interactive Educational Multimedia, 3, 27-37.

$\mathrm{Su}$, B. (2009). Effective technology integration: Old topic, now thoughts. International Journal of Education and Development using ICT, 5(2), 161-171.

Swanson, J. C., Meinert, D. B., \& Swanson, N. E. (1994). Business communications: A highly valued core course in business administration. Journal of Education for Business, 69(4), 235-239.

Thistead, R. A., \& Velleman, P. F. (1992). Computers and modern statistics. In D. Hoaglin \& D. Moore (Eds.), Perspectives on contemporary statistics (pp. 41-53). Washington, DC: Mathematics Association of America.

Tsai, C.-C., \& Chai, C. S. (2012). The "third"-order barrier for technology-integration instruction: Implications for teacher education. Australasian Journal of Educational Technology, 28(6), 10571060 .

Zeidner, M. (1991). Statistics and mathematics anxiety in social science students: Some interesting parallels. British Journal of Educational Psychology, 61(3), 319-328.

Zieffler, A., Garfield, J., Alt, S., Dupuis, D., Holleque, K., \& Change, B. (2008). What does research suggest about the teaching and learning of introductory statistics at the college level? A review of the literature. Journal of Statistics Education, 16(2), www.amstat.org/publications/jse/v16n12/zieffler.html. 